\title{
Ecos de Cor e Cór: relato de uma experiência cênica transversal
}

\author{
Ecos de Cor e Cór: report of \\ a transverse scenic experience
}

Viviane Rosa Juguero ${ }^{1}$

RESUMO

Ecos de Cor e Cór foi um espetáculo protagonizado por dezenas de professores de escolas públicas. Esse trabalho resultou de um processo de criação cênica, no qual acrobacias, máscaras, música e materiais cenográficos constituíram uma dramaturgia inspirada na Biologia do Amor, associando a Arte à Educação Ambiental, de forma transversal.

Palavras-chave: Dramaturgia. Artes Cênicas. Educação Ambiental.

\section{ABSTRACT}

Ecos de Cor e Cor was a theatre show starring dozens of teachers from public schools. The work is a result of a scenic creation process in which stunts, masks, music and scenographic materials have created a dramaturgy inspired by the Biology of Love, associating Art with Environmental Education in a transversal way.

Keywords: Dramaturgy. Performing Arts. Environmental Education.
Doutoranda no Programa de Pós-Graduação em Artes Cênicas da Universidade Federal do Rio Grande do Sul. ORCID: http://orcid.org/ oooo-0002-1048-4913 Contato:

vivianejuguero@yahoo.com.br 
É preciso ter coragem para falar de amor em nossa cultura ocidental contemporânea. É preciso coragem para defender que sem amor não há caminho para a transformação. É preciso também ter humildade para entender que agir com amor é um permanente aprendizado, que exige persistência e reavaliação contínuas, pois a ação amorosa atual está inserida em um contexto que a subjuga e renega. No livro "Amar e Brincar: Fundamentos esquecidos do humano", Humberto Maturana e Gerda Verden-Zöller defendem que o amor não é compreendido como um fenômeno constitutivo do humano em nossa cultura atual:

Nós, seres humanos modernos do mundo ocidental, vivemos numa cultura que desvaloriza as emoções em favor da razão e da racionalidade. Em consequência, tornamo-nos culturalmente limitados para os fundamentos biológicos da condição humana (2004, p. 221).

Os referidos autores defendem que em todos os domínios operacionais nos quais ocorrem as ações racionais existe um fundamento emocional. Nesse sentido, Verden-Zöller explana que é por meio da biologia do amor que surge a capacidade de coexistência social humana; e Maturana, por seu turno, explica que não é a razão que determina o que fazemos ou deixamos de fazer, mas sim, os desejos, preferências, medos e ambições que sentimos.

Durante o ano de 2015, ministrei a disciplina "Arte e Sustentabilidade na Educação Ambiental com Crianças", no curso de formação de professores do Ministério da Educação "O Lúdico na Educação Ambiental", realizado pela Universidade Federal do Rio Grande do Sul, por meio da Faculdade de Economia. Tal curso esteve sob a coordenação da Profa. Dra. Maria de Lurdes Furno, que idealizou as atividades com a previsão de uma apresentação final realizada pelos alunos, a qual ficou a cargo da disciplina que ministrei. O processo de construção artística e pedagógica da montagem do espetáculo Ecos de cor e cór, de minha autoria, é enfocado neste artigo como uma experiência transversal embasada na Biologia do Amor. Como autora desse artigo, procuro seguir a metodologia proposta por Daniela Versiani, na qual quem escreve busca manter uma postura autoetnográfica,

atenta à construção intersubjetiva de sua própria subjetividade, circunstanciada por trajetórias intelectuais e pessoais singulares, através de sua inserção em diferentes grupos socioculturais, do embricamento de curiosidades teóricas e escolhas racionais, afetivas e até mesmo casuais e contingenciais (2002, p. 71). 


\section{Contextualizando a cena}

Ao ser convidada para ministrar a disciplina referida anteriormente, tive uma sensação paradoxal. De imediato, fiquei identificada com a proposta, pois entendi o curso vinculado diretamente às experiências desenvolvidas no meu trabalho como artista e coordenadora do Bando de Brincantes. No entanto, incomodava-me a ideia de ter de, necessariamente, realizar um espetáculo de encerramento, o qual já tinha, inclusive, período e local determinados. $\mathrm{O}$ que me inquietava era a possibilidade de que a obrigação de realizar uma apresentação pudesse impedir o processo criativo a ser realizado com os alunos e que resultasse em algo parecido com a realidade predominante nas apresentações escolares, nas quais os alunos repetem falas mecanicamente e realizam marcações predeterminadas, sem participação ativa no processo de criação.

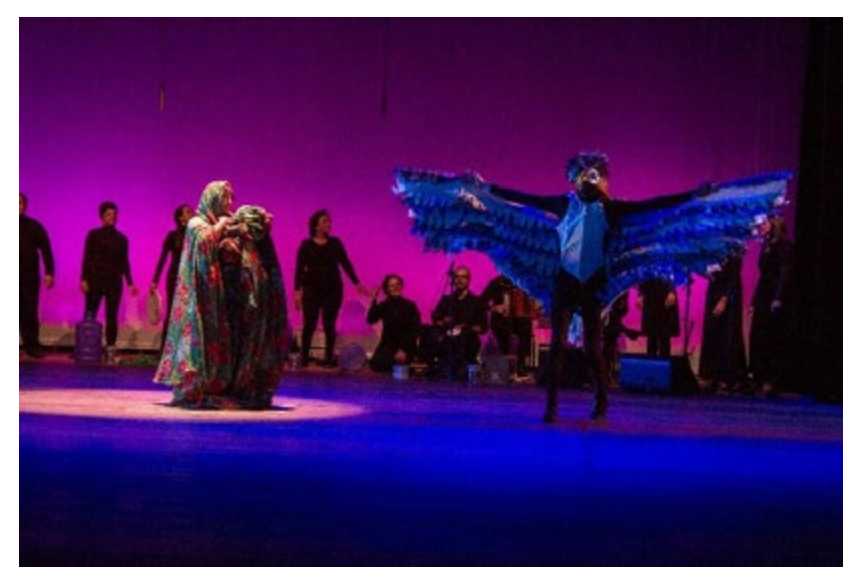

Figura 1. Ecos de Cor e Cór - Salão de Atos da UFRGS, Porto Alegre, 2015. Fonte: Acervo do curso.

No contexto do curso, o local da apresentação também estava previamente definido. Ela precisava acontecer no Salão de Atos da Universidade Federal do Rio Grande do Sul, um enorme auditório com 1174 lugares e com um palco frontal de generosas dimensões. Ao mesmo tempo, havia a previsão de que a disciplina teria um número elevado de alunos, podendo chegar a cem professores da rede pública de ensino, a maioria sem nenhum tipo de formação artística. O espaço de apresentação de um espetáculo é extremamente significativo e requer técnicas específicas de expressão e utilização de equipamentos. A projeção vocal em uma pequena sala é completamente diferente daquela necessária em um grande auditório. Além disso, a utilização de um microfone requer treinamento, em especial quando se trata de interpretação cênica associada à movimentação. Um som natural tem um significado distinto de um som mediado por amplificação e a utilização de equipamentos requer distintas técnicas de 
emissão vocal, projeção e entonação, as quais são determinantes na apreciação, compreensão e fruição do que é assistido. Todos esses fatores tiveram que ser levados em consideração para o planejamento do processo.

Outra questão preliminar era a informação de que a coordenadora do curso o haveria criado devido ao fato de ela ser a autora de um personagem ambiental, chamado Brasileco, e que haveria, por isso, a expectativa de que dito personagem entraria em cena na apresentação final, já que teria sido ele o motivo pelo qual a proposta do curso teria sido desenvolvida. A presença de um personagem infantil incitava à necessidade de repensar o papel que se tem atribuído às crianças enquanto "salvadoras do futuro", como se uma educação racional pudesse modificar os hábitos de amanhã, sem ter êxito nas atitudes de hoje. A esse respeito, Maturana e Verden-Zöller ressaltam que

é segundo o modo como vivemos nosso emocionar - e em particular nossos desejos -, e não de acordo com o nosso raciocínio, que viverão nossos filhos no mundo que geraremos - eles e nós - ao nos transformar, construindo assim a história em nosso viver (2004, p. 17).

A presença do Brasileco na dramaturgia precisava ser pensada com afeto e responsabilidade, visto que as crianças são agentes de mudança cultural somente na medida em que elas fazem parte de um processo comunitário de alteração de hábitos e desejos que os gera:

Uma nova cultura surge por meio de uma dinâmica sistêmica, na qual a rede de comunicações em que a comunidade em processo de mudança cultural vive, modifica-se, guiada e demarcada precisamente pela nova configuração do emocionar, que começa a se conservar na aprendizagem das crianças (MATURANA; VERDENZÖLLER, 2004, p. 14).

Como visto, não eram poucos os desafios para criar um planejamento artístico e pedagógico que pudesse atender às necessidades dessa estrutura preliminar, sem, no entanto, prejudicar um processo de aprendizagem e amadurecimento do grupo em relação ao tema central da disciplina e do curso: a relação entre Arte e Educação Ambiental. Assim, busquei construir uma proposta na qual o processo fosse tão ou mais importante que a apresentação final. O objetivo era não somente abordar a temática ambiental com o público que fosse assistir à peça, mas, especialmente, propiciar uma vivência estética aos alunos do curso, voltada a uma compreensão e percepção holística do ser humano. 
Como sensibilizar os professores, ampliando suas possibilidades expressivas e suas reflexões sobre a importância da Arte na formação humana como um todo, e na Educação Ambiental, especificamente? Como trabalhar a criatividade, em um contexto no qual era necessário fazer uma apresentação final, sem que houvesse tempo hábil para uma criação dramatúrgica coletiva, devido ao pequeno período de duração da disciplina?

Como proporcionar uma nova percepção sobre as possibilidades de relação entre Arte e Educação, desvinculando das práticas didatizantes presentes na ainda predominante "educação bancária" apontada por Paulo Freire (2016), na qual o educador não dialoga com os alunos, supostamente ignorantes, impondo a eles conhecimentos que devem ser decorados mecanicamente?

Como buscar um caminho que possibilite um desenvolvimento expressivo desvinculado dos estereótipos tão propagados no ambiente escolar e amplamente denunciados por artistas que trabalham seriamente a arte para crianças, como Pupo (1991), Gil (1999), Camarotti (2005) e Juguero (2014), dentre outros?

Como criar um planejamento pedagógico e artístico inicial, deixando lacunas a serem preenchidas pelas ideias, expectativas, anseios e criatividade dos alunos do curso? Como ensinar e estar simultaneamente aberta a aprender? Como propor novas formas de comunicação sem desqualificar as propostas dos alunos e incitá-los a buscar novas possibilidades, novas reflexões e novos pontos de vista? Como propor a eles uma transformação e, ao mesmo tempo, estar aberta a transformar a mim mesma?

Em busca de possíveis respostas, trilhei um caminho norteada pelas ideias construídas pela Biologia do Amor, muito embora, inicialmente, essa não fosse uma opção conscientemente sistematizada, já que me alicerçava em diversos referenciais que influenciam meu trabalho - os quais também podem ser relacionados à obra aqui comentada -, como as propostas de Bertold Brecht (1967; 1972), Augusto Boal (2008) e Paulo Freire (2016), cujas relações optarei por fazer em estudos futuros.

Desde o princípio, tive a convicção de que minha disciplina precisava enfocar a necessária mudança dos paradigmas culturais geradores dos desejos mobilizadores das ações humanas que resultam em danos sociais e ambientais. Humberto Maturana (2004) defende que para que aconteça o surgimento de uma nova cultura é preciso "reconhecer as condições de mudança emocional sob as quais as coordenações de ações de uma comunidade podem se modificar" (2004, p. 35).

Dessa forma, busquei criar um planejamento no qual as 
distintas preparações para a apresentação buscassem desenvolver a sensibilidade, o pensamento crítico e múltiplas percepções (sensoriais, cognitivas, axiológicas, simbólicas e sócio-históricas), propondo a superação de obstáculos objetivos e subjetivos, por meio da expressividade teatral, na realização de movimentações acrobáticas e extracotidianas; no canto e no acompanhamento musical; nas criações e manipulações de objetos cênicos; e, evidentemente, na orquestração de todos os elementos em cena.

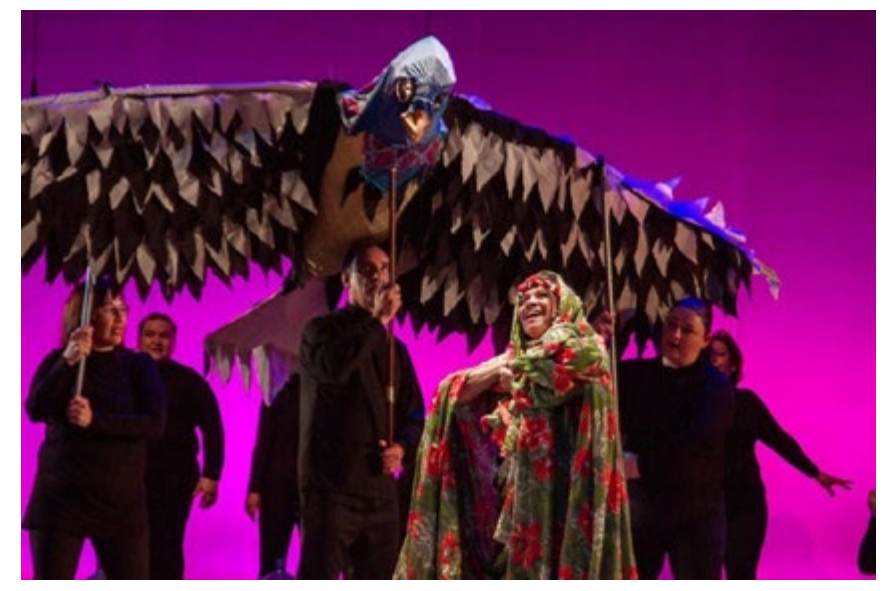

Figura 2. Ecos de Cor e Cór Salão de Atos da UFRGS, Porto Alegre, 2015. Fonte: Acervo do curso.

Sobre o processo

Com o objetivo de ampliar o trabalho colaborativo e as experiências estéticas dos alunos, propus à coordenadora Maria de Lurdes Furno, que minha disciplina tivesse a participação de artistas do Bando de Brincantes, os quais ministrariam oficinas e participariam do processo de construção do espetáculo protagonizado pelos professores, estando em cena junto com eles. A proposta foi acolhida com entusiasmo pela coordenadora que nunca mediu esforços para conseguir todas as condições necessárias à plena realização de todas as etapas do processo. Assim, educadores, artistas e técnicos do Bando de Brincantes participaram do trabalho.

Conforme os objetivos que pretendia atingir, escolhi as oficinas a serem ministradas e os profissionais que seriam responsáveis por elas. Fizemos reuniões nas quais apresentei o planejamento geral das atividades, contando com a participação ativa e criativa dos brincantes-oficineiros na formatação final da proposta. Os encontros com os alunos foram conduzidos por profissionais de cada especialidade contando com a participação coletiva de todos os brincantes educadores. Assim, foram realizadas oficina de acrobacias (ministrada por Éder Rosa); de máscaras (ministrada por Jessé Oliveira); de trilha sonora (ministrada por mim, Marcelo Rocha e Wagner Madeira); de brincadeiras em cena 
(ministrada por Carmen Lima e por mim), além dos encontros chamados de "Ateliê Aberto", realizados sob a coordenação de Wagner Madeira, Éder Rosa e Carmen Lima, na confecção de adereços cênicos; e de Marcelo Rocha, na confecção de instrumentos de percussão.

O processo se deu de forma prático-reflexiva. Dessa maneira, as reflexões pedagógicas eram apresentadas no decorrer das atividades práticas - oficinas artísticas e ensaios -, dentro de uma articulação orgânica, na qual os princípios teóricos estavam diretamente relacionados às técnicas e concepções artísticas propostas. De forma complementar, ministrei encontros teóricos e aulas à distância, abordando a lógica lúdica do pensamento infantil, a relação da arte com a educação, bem como a percepção de que a arte é uma das formas do ser humano se reconhecer como parte integrante da natureza.

Nas oficinas, as cenas não eram abordadas diretamente. Por vezes, pequenos laboratórios de partes do texto eram experimentados com base no que estava sendo trabalhado naquele encontro. As músicas e efeitos sonoros eram desenvolvidos na oficina de música, mas sem estarem necessariamente vinculados à ação da cena. Após o período de oficinas, compreendido entre agosto e setembro de 2015, iniciaram-se os ensaios, os quais aconteceram nos meses de outubro e novembro do mesmo ano, culminando na primeira apresentação, realizada no dia 24 de novembro. Devido ao êxito desta realização, outra apresentação foi a público no dia 24 de março de 2016, no mesmo local.

Os ensaios foram conduzidos por mim, agora na posição de diretora artística, contando com a assessoria de direção de Jessé Oliveira e com a orientação técnica e atuação dos demais brincantes já citados. Nos ensaios, os músicos brincantes Toneco da Costa e Renato Müller passaram a atuar tocando violão e gaita ponto, atuação essa de fundamental importância na construção da atmosfera sonora junto à Marcelo Rocha e os demais integrantes do grupo. Durante o processo, os alunos do curso puderam descobrir em quais momentos da dramaturgia se identificavam melhor e como poderiam atuar junto aos brincantes profissionais que estavam em cena, respaldados nas orientações da direção.

Além dos aspectos da criação artística, a proposta de construção da apresentação de Ecos de cor e cór buscou oportunizar um trabalho no qual fosse possível associar prazer e disciplina, respeito ao planejamento e criatividade, expressão pessoal e cumplicidade, rigor e flexibilidade, em uma permanente relação dialética transformadora. O êxito do trabalho dependia de uma articulação colaborativa, construída coletivamente. A percepção dessa 
necessidade foi transformadora para todos os envolvidos, resultando na compreensão de que a mesma é fundamental para mobilizar ações que resultem em efetivas melhorias das condições ambientais.

No decorrer do processo que será descrito a seguir, todos fomos amadurecendo como grupo e reconhecendo os papeis que cada um ocupava e as posturas necessárias para o desenvolvimento de um trabalho efetivamente colaborativo:

A democracia não opera como poder, autoridade ou exigências de obediência. Muito ao contrário, ela se realiza por meio de condutas que surgem de conversações de co-inspiração que geram cooperação, consenso e acordos (MATURANA, 2004, p. 96).

\section{A proposta original da dramaturgia}

Devido à apresentação cênica presente no planejamento do curso, todas as ações artísticas e pedagógicas da disciplina foram criadas no intuito de viabilizar um processo de vivência efetiva das diversas artes envolvidas em uma encenação, tendo, no entanto, clareza no objetivo final a ser atingido por todos: a apresentação de um espetáculo. Por essa razão, era necessário haver uma dramaturgia prévia que orientasse um caminho a ser seguido, mas que estivesse aberta às colaborações criativas que surgiriam durante o processo, como acontece nas situações em que um texto teatral é montado por profissionais.

Evidentemente, existem inúmeras outras maneiras de montar um espetáculo teatral, inclusive, sem nenhum texto prévio. No entanto, diversos aspectos foram determinantes para que eu decidisse a utilização de uma dramaturgia pré-definida como base da montagem. Conforme já referido, o tempo de duração da disciplina não viabilizaria uma construção textual coletiva, visto a complexidade deste tipo de processo. Além disso, tomar como fundamento os referenciais que os alunos já possuíam parecia ser um bom caminho, tanto para valorizar seus conhecimentos na área, quanto para propor novas percepções. Afinal, somente o conhecido pode se transformar. Como perceber uma transformação no desconhecido se não o conheço? Esse foi um dos aspectos importantes para eu decidir utilizar uma dramaturgia prévia, visto que trabalhar uma montagem cênica baseada em um texto teatral é um procedimento bastante difundido nas escolas.

E por que uma dramaturgia original? Como sou dramaturga, optei por criar uma proposta que contemplasse o que desejava 
trabalhar como professora, dentro da realidade do contexto no qual a montagem da encenação estava inserida: dezenas de professores sem formação artística, um palco enorme para mais de mil espectadores, pouco tempo de trabalho (apenas um semestre) e, principalmente, com o objetivo de desenvolver princípios artísticos e pedagógicos vinculando a Arte à Educação Ambiental. Além disso, era essencial abordar a questão da realização de obras artísticas que dialogassem com a lógica lúdica do pensamento infantil, pesquisa que desenvolvo desde o início da trajetória do Bando de Brincantes (2003), que abordei em meu mestrado (2014) e que sigo aprofundando no doutorado e em meus trabalhos artísticos atuais.

Nesse sentido, pensei ser importante criar uma linguagem transversal que possibilitasse às crianças dialogar plenamente com a obra - de acordo com as características de seu pensamento -, e, aos adultos, vincular as imagens às metáforas e abstrações características do seu próprio universo. Quis propor um caminho no qual os próprios professores (alunos no curso) se sentissem desafiados a relacionar ludicidade e pensamento crítico, evitando momentos em que referenciais adultos resultassem em incompreensão por parte das crianças. Meu objetivo era que a participação ativa na construção dos sentidos fosse possível por meio de diversas vias, resultando em uma plena interação com a obra, sem lacunas de incompreensão, mas com possibilidades de diversidade de formas de pensamento, que resultassem em múltiplas leituras vetorizadas por um sentido comum. Esse sentido comum nada tem a ver com leituras estanques e mensagens doutrinárias, mas sim, com o caminho que busca apresentar perguntas instigantes e não respostas rigidamente estabelecidas (JUGUERO, 2014).

A dramaturgia de Ecos de cor e cór, desde o princípio, foi concebida em sentido amplo, ou seja, como a construção do discurso espetacular, por meio da estruturação dos distintos elementos cênicos (movimentação, texto, cenário, música, figurinos, etc.), regidos por uma concepção estética que determina a relação de complementariedade e vetorização (PAVIS, 2010) na estrutura discursiva como um todo. Com o objetivo de ampliar as percepções, incitar o pensamento crítico e reflexivo foi desenvolvida essa composição plurissignificativa da cena, cuja construção discursiva se dá por meio de diferentes signos organizados simultânea e consecutivamente (UBERSFELD, 2010), em diálogo com os referenciais do público (DE MARINIS, 2005).

Conforme Maturana e Verden-Zöller, "se cada emoção configura um domínio particular de ações, fazemos coisas diferentes sob distintas emoções" (2004, p. 238). Por essa razão, o texto foi 
concebido para trabalhar e sensibilizar as pessoas como um todo, ampliando as percepções que cada um tem de si, como um ser de natureza social e animal. A intenção era provocar sensações de prazer, de confiança em si e no outro, possibilitando que a própria realização da apresentação passasse a ser um objeto de desejo de todos, em uma ação coletiva multissensorial. Minha experiência anterior na criação de arte para a Primeira Infância junto a crianças de zero a seis anos - refiro-me a "Jogos de inventar, cantare dançar" (JUGUERO, 2010; 2014) -, trouxe-me a comprovação de que o processo ecoa no resultado final de forma extremamente eloquente. Assim, estabeleci uma relação com o grupo na qual nossa trajetória de cumplicidade e engajamento - na busca de uma intimidade física e emocional -, fosse esteticamente perceptível em nossa apresentação.

Enquanto cada um de nós constrói sua própria realidade como seu domínio de correlações sensório-motoras em suas interações com os outros, todos construímos, em conjunto, os padrões de significado que constituem os diversos mundos que vivemos (VERDENZÖLLER, 2004, p. 176).

Desse modo, a Educação Ambiental precisava estar não somente na temática da apresentação, mas, principalmente, na corporeidade dos intérpretes, em suas vozes, em seus olhares e suas emoções. Para tanto, o trabalho enfocou o desenvolvimento da expressividade corporal, vocal, visual e narrativa por meio de atividades teatrais, musicais, plásticas e literárias, de forma que fossem reconhecidos os inúmeros aspectos contidos em uma realização artística, desde o processo até a apresentação. O texto era um pretexto para propor um processo de sensibilização íntegra e integral, de todos e de cada um. O que eu considerava imprescindível era enfocar a Educação Ambiental vinculada às alterações culturais profundas, com base na ideia de que "se quisermos viver num mundo diferente, devemos mudar nossos desejos" (MATURANA, 2004, p. 114).

Sobre esse tema, Maturana salienta que à medida que nos damos conta do fundamento emocional de todo o sistema racional, é possível que cada um se responsabilize por suas próprias escolhas, sem, no entanto, poder fragmentar razão e emoção.

Para que os recursos naturais, os valores, as ideias, ou os símbolos apareçam em nossas diferenciações como fatores ou elementos que norteiam o curso de nossa vida, já surgira antes independentemente deles próprios - o emocionar que os tornou possíveis como orientadores de nosso viver (MATURANA; VERDEN-ZOLLER, 2004, p. 11). 


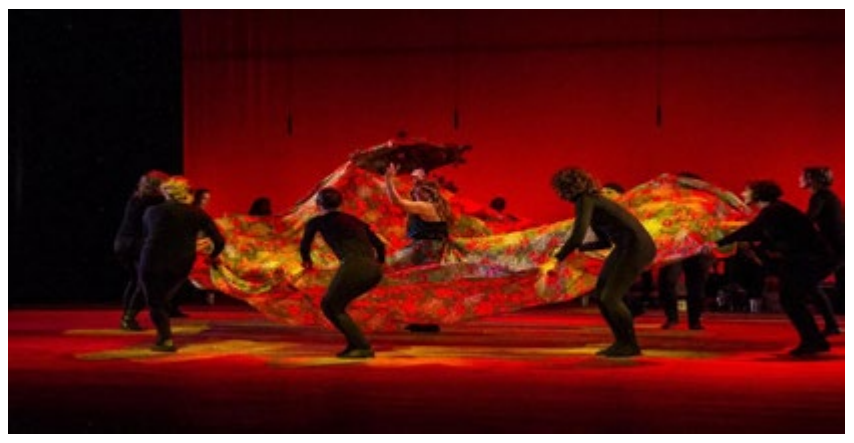

Figura 3. Ecos de Cor e Cór - Salão de Atos da UFRGS, Porto Alegre, 2015. Fonte: Acervo do curso.

Concepção geral do espetáculo

Em Ecos de cor e cór, o discurso espetacular prescinde da fala, utilizando da palavra somente na poesia das canções, as quais são parte integrante na composição dos múltiplos signos da cena e completam seu sentido na relação plural com esses mesmos signos.

A encenação foi concebida em uma linguagem poética e afetiva, com o objetivo de despertar a sensibilidade e a reflexão. A escolha de evitar textos com diálogos explicativos tencionava propiciar uma compreensão mais ampla da elaboração das significações e contribuir também para o desenvolvimento de uma leitura mais aguçada da realidade cotidiana.

Vale salientar que, em diversos momentos, algumas pessoas do grupo sentiram falta de uma narrativa que elucidasse a cena e perguntaram se não haveria um narrador que explicaria as ações para que o público pudesse entender. Esse valioso questionamento propiciou uma atenta percepção de todo o processo, o qual colocou em evidência que a comunicação humana se dá por meio de composições complexas, sem estar necessariamente subordinada à palavra e a fixas significações.

Por outro lado, o trabalho apresenta uma estrutura narrativa tradicional, com apresentação do tema, desenvolvimento, clímax e desfecho. A familiaridade com essa forma de elaboração do enredo proporcionou um envolvimento criativo dos participantes, manifestado nas sugestões para formas de movimentação cênica, confecção de materiais e para a dramaturgia (como quando a aluna Kátia Schmitt sugeriu que fossem trabalhados somente animais da fauna brasileira).

A concepção da encenação abordou a Educação Ambiental por meio de imagens eloquentes. Movimentações acrobáticas simbólicas, grandes objetos cênicos, máscaras, sonoplastia e trilha sonora ao vivo representaram diversos ambientes e atmosferas com a intenção de instigar a sensorialidade e a cognição. As cenas dedicadas à harmonia da natureza foram vinculadas a imagens artesanais de manifestações da cultura brasileira. Em contra- 
posição, cenas que ilustravam o consumo desenfreado estavam ligadas a imagens da produção industrial despersonalizada.

No título, eco de ecologia, eco de efeito sonoro, cor de colorido e cór ${ }^{2}$ de coração, de corpo e de comunicação. Como dar cor ao que sei de cór? É interessante relatar que quando criei o título "Ecos de Cor e Cór" não percebi que gerava a onomatopeia Cocoricó, o que foi ressaltado pelo brincante Jessé Oliveira ao ler a primeira versão do texto. Ao perceber a potencialidade desse significado, integrei-o à dramaturgia. Assim surgiu a figura do galo, como um alerta para acordar e "a - cor - dar" pode ser interpretado também no sentido de "dar a cor". Como decorrência dessas possibilidades interpretativas, as ações foram pensadas no sentido de motivar os participantes do projeto a agir com afeto, com o objetivo de despertar a consciência de atuadores e espectadores, bem como de dar cor à temática da natureza, ou seja, realçar a importância concreta e afetiva dessa articulação entre as pessoas e das pessoas com a natureza. Esse canto de acordar também pode significar a concretização de um acordo, como no caso da cumplicidade entre os personagens do galo e da criança, seres individuais que compõe a diversidade da coletividade.

Para destacar a singularidade da figura infantil, o personagem Brasileco foi representado por meio de uma técnica distinta das demais figuras cênicas. Era um boneco de manipulação direta, do tamanho da estatura real de uma criança de aproximadamente oito anos, elaborado por Wagner Madeira, com base na ilustração de Bruna Mársico, criada para o livro Brasileco: o início da aventura, de Malu Furno.

Em Ecos de cor e cór, Brasileco vivencia e reage às situações, na mesma medida do que ocorre com as crianças que estão inseridas em suas próprias culturas e com elas dialogam. Ele mantém a essência matrística da cooperação associada à ingenuidade infantil. Sua presença gera a reflexão sobre a infância arraigada nos distintos contextos e sobre como esses contextos constituem a criança. Por trazer o Brasil em seu nome, o personagem cria uma identificação com cada pessoa da plateia e, ao mesmo tempo, por estar em um contexto maior, associa o país ao ambiente global do qual faz parte.

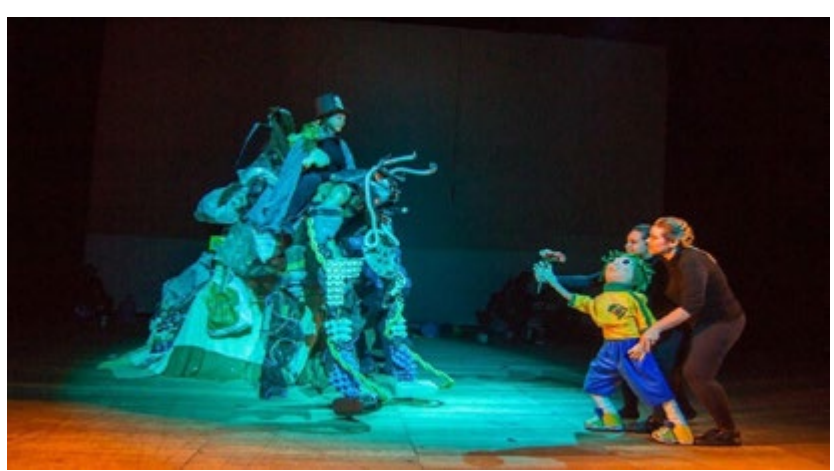

Figura 4.

Ecos de Cor e Cór - Salão de Atos da UFRGS, Porto Alegre, 2015. Fonte:Acervo do curso.
2.

Apesar de as novas regras ortográficas terem suprimido o acento da palavra cór, opto por mantê-lo por uma questão distintiva. 
O processo de encenação de Ecos de cor e cór propiciou aos alunos do curso uma percepção de organicidade e de integração na cena teatral, além da vivência da construção de uma representação fictícia simbólica, cujos princípios de realização estão embasados na entrega real de cada um e na cumplicidade existente entre os participantes. Assim, foram realizadas brincadeiras em diversos momentos das oficinas e ensaios, buscando que a atenção do grupo estivesse afetivamente vinculada ao momento presente, criando uma profunda conexão entre todos os envolvidos. Segundo Maturana e Verden-Zöller,

brinca-se quando se está atento ao que se faz no momento em que se faz. Isso é o que agora nos nega nossa cultura ocidental, ao chamar continuamente nossa atenção para as consequências do que fazemos e não para o que fazemos (2004, p. 230).

A intenção era evidenciar que a brincadeira possui diversos elementos em comum com a realização de uma intepretação teatral orgânica (JUGUERO, 2014), havendo, no entanto, diferenças fundamentais, visto que a criação artística exige o domínio de técnicas profissionais bastante distintas da espontaneidade demonstrada na brincadeira. Ao mesmo tempo, a experiência propõe um novo olhar sobre a forma como os adultos ocidentais contemporâneos costumam definir a atividade de brincar, como algo descomprometido, bobo e relaxado, muitas vezes associado à falta de disciplina ou de concentração. Ao contrário, a brincadeira é uma atividade importantíssima, de extrema concentração para a criança, associada à investigação e ao divertimento. Essa combinação é subversiva em relação aos padrões de pensamento patriarcais, os quais valorizam a intencionalidade e o controle, sempre projetando a produtividade futura. Para Verden-Zöller "nossa atenção está tão orientada para os resultados do que fazemos que raramente vivemos o nosso fazer como um ato no presente" (2004, p. 140).

$\mathrm{Na}$ verdade, tanto a atuação teatral como a brincadeira só acontecem plenamente se o foco energético e afetivo de quem age estiver completamente entregue ao momento presente. Nesse sentido, Verden-Zöller afirma que "não são os movimentos ou as operações realizadas que caracterizam um comportamento específico como brincadeira ou não, mas sim a atenção (orientação interna) sob a qual ele é vivido enquanto se realiza" (2004, p. 145).

Um objetivo pedagógico fundamental nessa montagem foi o de distanciar a expressividade teatral dos estereótipos propagados nas escolas e da artificialidade da interpretação que costuma estar 
presente nesse ambiente. A intenção de demonstrar uma ação é um equívoco reincidente nas encenações escolares. Isso resulta na realização de cenas estereotipadas e sem energia, criadas sem motivação interior, como quando um adulto finge estar brincando, sem se envolver de fato com o ato de brincar.

Uma ação com um objetivo, vivida como brincadeira - ou seja, com a atenção do ator na ação e não no possível resultado -, de uma maneira que lhe permita ver os outros, ocorre na biologia do brincar. Mas uma ação propositiva, vivida com a atenção posta nos resultados, acontece na biologia da instrumentalização das ações que não percebem o viver no presente. Portanto, não percebe a negação do outro que isso implica (VERDEN-ZÖLLER, 2004, p. 202).

Quando uma criança brinca, todo o seu corpo está envolvido emocional, psíquica e fisicamente, em uma completa integração. Ao mesmo tempo, ela precisa contar com a cumplicidade de todos os participantes, pois há um acordo tácito de respeito às regras lúdicas que regem essa ação (ELKONIN, 2009). Além disso, existe uma dupla enunciação (UBERSFELD, 2010) no reconhecimento simultâneo de si mesma e da representação que realiza. Ao brincar de ser professora, por exemplo, a criança vivencia essa personagem de corpo e alma, sem jamais perder a percepção de si mesma. Dessa maneira, a atuação é VERDADEIRA e não é "de mentirinha", visto que todos os envolvidos compactuam com o caráter de fantasia que rege a brincadeira e contribuem na construção dela. A esse respeito, Maturana e Verden-Zöller refletem que

perdemos nossa consciência social individual à medida que deixamos de brincar. E assim transformamos nossas vidas numa contínua justificação de nossas ações em função de suas consciências, num processo que nos torna insensíveis em relação a nós mesmos e aos demais (2004, p. 232).

A mentira pressupõe que alguém ignore a verdade. No teatro e na brincadeira acontece exatamente o contrário, pois todos são cúmplices na construção fictícia, em uma sintonia lúdica e criativa. Quando as crianças brincam, se divertem muito, apesar de essa ser uma atividade que requer concentração, disciplina e cumplicidade, em um envolvimento integral de corpo, mente, espírito e afeto. Retomar essa postura foi o objetivo da realização de brincadeiras durante o curso, já que a complexa criação de um espetáculo depende de uma ação coletiva vinculada à entrega e ao empenho de todos os envolvidos no processo. Vivenciar as brincadeiras foi determinante na construção da postura desse trabalho. A adequação à encenação teatral é composta de uma contradição 
dialética fundamental, na qual o rigor de preparação para uma apresentação não pode, em hipótese alguma, suprimir a vitalidade e a entrega ao momento presente, sem as quais, a verdadeira atuação artística desaparece. No processo aqui focalizado, o envolvimento afetivo e a cumplicidade entre o grupo tiveram um papel imprescindível tanto na intensa entrega à atuação quanto na experiência ambientalista embasada na Biologia do Amor, já que, "sem um desenvolvimento adequado do sistema nervoso no amor, tal como vivido no brincar, não é possível aprender a amar e não é possível viver no amor" (MATURANA; VERDEN-ZOLLER, 2004, p. 245).

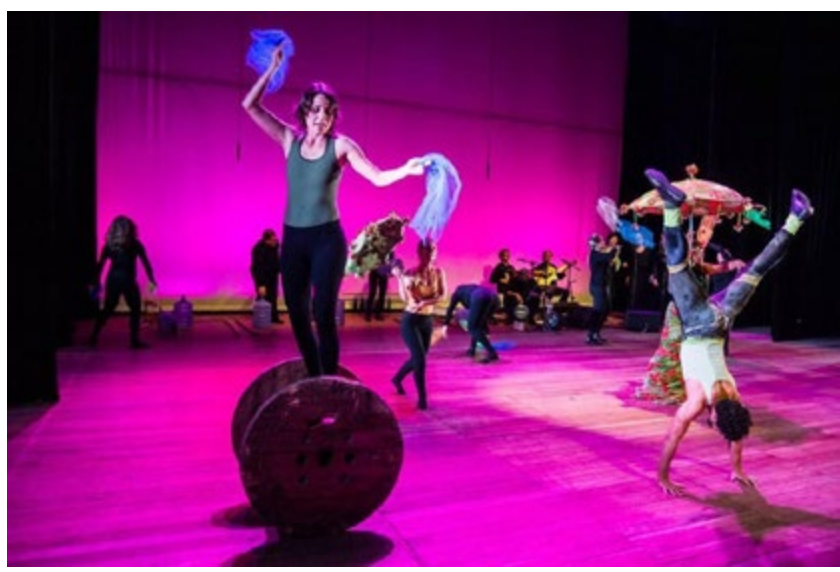

Figura 5 . Ecos de Cor e Cór - Salão de Atos da UFRGS, Porto Alegre, 2015. Fonte: Acervo do curso.

Corpos de cór; corpos com cor

O trabalho com acrobacias estimulou os educadores a redescobrir seus corpos, identificando neles potencialidades e limitações. Possibilitou ainda que movimentos condicionados socialmente, realizados de cór, fossem tornados conscientes e, ao mesmo tempo, que cada um pudesse dar cor à sua corporeidade, desenvolvendo novas possibilidades de movimentação. Para Verden-Zöller (2004), cada pessoa se constitui segundo o modo com que se move e com base na maneira com que compartilha o toque, constituindo espaços de ação na transformação de sua corporeidade.

Os padrões de comportamento impostos pelo ambiente social cotidiano e a repetição mecânica diária dos mesmos movimentos diminui a percepção da singularidade corpórea de cada indivíduo. Assim, a percepção de si mesmo acontece de forma fragmentária, na observância da aparência de características físicas externas como algo dissociado do processo de desenvolvimento do pensamento. Por sua vez, esse dilaceramento pessoal resulta em uma consequente desnaturalização das relações sociais e ambientais. 
Nossa separação cultural de espírito e corpo, assim como a insensibilidade em relação à corporeidade que implica essa separação junto com a separação entre os seres humanos e a natureza, que acompanha -, resulta numa falta fundamental de confiança nos processos naturais em muitas áreas básicas da existência humana. Essa falta de confiança é frequentemente negada com afirmações de admiração da sabedoria da natureza. Mas é continuamente reafirmada num discurso recorrente sobre as forças naturais que tem de ser dominadas ou controladas (VERDEN-ZÖLLER, 2004, p. 128).

A movimentação diferenciada experimentada na oficina de acrobacias propiciou uma consciência mais profunda da corporeidade, assim como auxiliou no reconhecimento do ser humano como um animal integrante da natureza. Portanto, ao realizar um "rolinho" (cambalhota) ou ao "plantar uma bananeira" (parada de mão), os professores perceberam e registraram fisicamente formas extracotidianas de locomoção (BARBA, 1995), experimentando agachamentos, movimentos sinuosos de coluna, maneiras de rastejar, de girar o quadril ou de expandir os ombros. Dessa forma, ainda que a ação acrobática não fosse realizada na íntegra, houve a descoberta de distintas formas de mobilidade e expressão.

Nossa consciência operacional do mundo em que vivemos é uma expansão de nossa consciência corporal. Os mundos que vivemos surgem como domínios de ações enquanto realizamos nossa corporeidade em nossas coordenações sensório-motoras (MATURANA; VERDEN-ZOLLER, 2004, p. 231).

Nos encontros ministrados por Éder Rosa, os alunos do curso puderam experienciar movimentos acrobáticos solo, em dupla e em grupo, além de alongamentos e exercícios preparatórios. Nessas atividades, o propósito foi aprimorar o condicionamento físico e a consciência corporal, assim como ampliar a expressividade e aprofundar a relação de confiança entre o grupo, em momentos em que o prazer e a criatividade se associaram à disciplina e à organização. Essa vivência objetivou estimular reflexões sobre as abordagens lúdicas e artísticas realizadas em sala de aula e possibilitar novas formas de expressão dos professores participantes do curso, tanto na apresentação de Ecos de cor e cór, quanto em outros contextos. Os desafios propostos resultaram em uma entrega efetiva, associando concentração e diversão, como fazem as crianças em suas brincadeiras, por meio de um envolvimento afetivo, psíquico, cognitivo e motor complexo, integrado e orgânico.

A experiência do trabalho gerou atitudes que denotaram a compreensão de que as relações interpessoais de confiança e desconfiança ocorrem na interdependência entre as dinâmicas 
corporais e a aceitação mútua, conforme defendido por Maturana e Verden-Zöller (2004). A oficina de acrobacias ocasionou uma atmosfera constante de cumplicidade, tanto nos momentos de experimentação individual quanto nos movimentos com duas ou mais pessoas. $O$ resultado da integração afetiva e corporal nesse contexto, revelou, por outro lado, que

quando o interagir em desencontro emocional se transforma em um modo cotidiano de coexistência para os membros de uma família ou cultura, estes inevitavelmente entram numa crescente dinâmica de incongruência corporal, que reduz continuamente suas possibilidades de operar nas coordenações comportamentais consensuais da família ou cultura (VERDEN-ZÖLLER, 2004, p. 149).

O desenvolvimento dessas atividades demonstrou a potência da sensação de fazer parte de uma ação coletiva e revelou que esse trabalho afetivamente engajado é fundamental à Educação Ambiental, já que propicia descobertas e superações, independentemente da idade ou da forma física das pessoas, o que culmina na desconstrução de preconceitos arraigados em nossa sociedade.

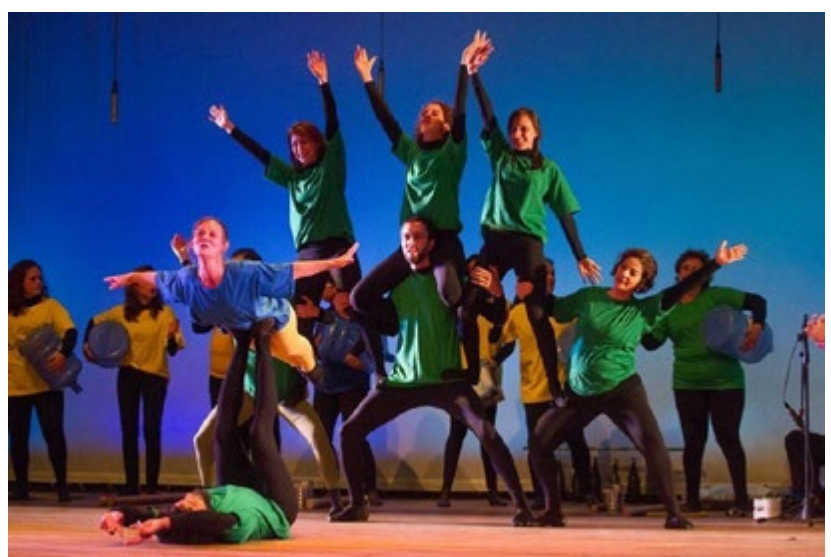

Figura 6. Ecos de Cor e Cór - Salão de Atos da UFRGS, Porto Alegre, 2015. Fonte: Acervo do curso.

\section{Ecos sonoros}

A música esteve presente nas atividades desenvolvidas na disciplina desde o primeiro encontro. Além das oficinas dedicadas especialmente às sonoridades, envolvendo as canções do espetáculo e a sonoplastia, o trabalho musical aconteceu em todos os ensaios, sempre contando com aquecimento vocal antes das atividades e das apresentações. A voz foi trabalhada por meio de exercícios nos quais ela é entendida como parte integrante do corpo como um todo, com base em técnicas que estudei com a professora Marlene Goidanich ${ }^{3}$. Esse trabalho de sensibilização dialoga com

3.

Professora de expressão vocal no Departamento de Arte Dramática do Instituto de Artes da Universidade Federal do Rio Grande do Sul de 1986 a 2001. 
a relevância que o ritmo, a música e os movimentos possuem na formação da consciência humana, desde a primeira infância, como enfatiza Verden-Zöller:

Os ritmos corporais, e o fluxo das configurações de coordenações sensório-motoras, no estreito contato corporal que acontece entre mãe e filho, são a base da qual surge a consciência humana (2004, p. 150).

Por essa razão, o trabalho com aquecimento de articulações, alongamentos e respiração, precedia um momento no qual se trabalhava dicção, projeção vocal, naturalidade na voz e afinação, com o objetivo de ampliar a percepção auditiva e conduzir cada um dos alunos a reconhecer a própria voz em meio ao conjunto. Esse aspecto é fundamental na Educação Ambiental, tanto para refletir sobre a poluição sonora à qual nossa sociedade contemporânea é cotidianamente submetida, quanto pela consciência de que a escuta é imprescindível nas ações colaborativas. Cabe salientar que a fase de aquecimento corporal e vocal é um momento de profunda comunhão e conexão entre o grupo, indispensável para preparar a concentração necessária aos ensaios e apresentações. Esse procedimento vem ao encontro do pensamento de Verden-Zöller (2004) quando a autora salienta que o ser humano desenvolve sua autoconsciência no domínio de relações espaciais e temporais, o que possibilita o resguardo da individualidade em meio à harmônica integração social.

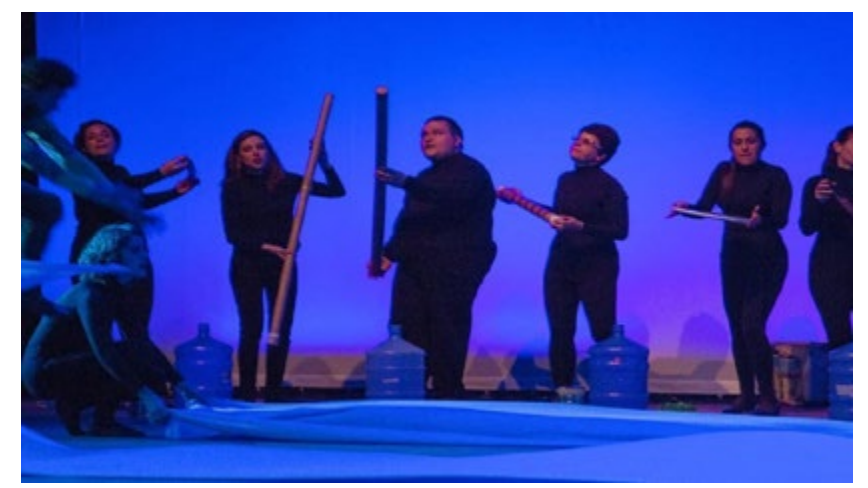

Figura 7.

Ecos de Cor e Cór - Salão de Atos da UFRGS, Porto Alegre, 2015. Fonte: Acervo do curso.

Na dramaturgia de Ecos de cor e cór, a música tem um papel essencial, por ser condutora da ação. A sonoridade, além de criar as distintas atmosferas, faz parte de um sistema que move a ação e provoca a reflexão. As letras das canções são as únicas palavras ditas no espetáculo, construindo as possibilidades de significação tanto no que concerne às características melódicas, harmônicas e rítmicas da própria música, quanto na relação que esses elementos estabelecem com a dinâmica da cena, uma vez que dialogam com os demais fatores sinestésicos, lúdicos e cenográficos. 
Criei as composições originais de forma integrada a uma dramaturgia concebida como um complexo sistema de signos. Dessa forma, as letras não são ilustrativas, não descrevem nem explicam as cenas, mas sim, sugerem possibilidades de sentidos. Minha intenção foi de que os signos literários e sonoros estivessem associados aos visuais e estimulassem quem aprecia a cena a construir suas percepções e significados baseando-se em seus próprios referenciais. Optei por compor letras, melodias e harmonias singelas e afetivas, inspirada no investimento amoroso que o grupo dedicava à Educação Ambiental. Ao mesmo tempo, a sonoridade de cantiga de roda e de ninar remete ao papel que a música possui na construção da autoconsciência, evocando o que Verden-Zöller chamou de ritmos fundamentais:

\begin{abstract}
Escutamos o ritmo de nosso coração e seguimos a frequência de nossas pulsações, mergulhando numa fina rede de sons que criam um espaço. Assim, simplesmente contamos ao compasso do bater de nossos corações ou brincamos cantando qualquer coisa, seguindo o ritmo dos intervalos elementares de nossas pulsações. Recuperamos a velha e quase esquecida tradição do acalanto e das canções de ninar, e descobrimos que elas evocam nossos ritmos fundamentais (VERDEN-ZÖLLER, 2004, p. 151).
\end{abstract}

A trilha sonora instrumental da apresentação foi criada no decorrer dos ensaios pelos músicos Toneco da Costa, Renato Muller e Marcelo Rocha, e resultou numa integração da composição rítmica com a dinâmica proprioceptiva da cena. A construção sonora caracterizou-se por dialogar com as posições físicas no espaço e por influenciar as formas de deslocamento, postura e consequente equilíbrio. Sonoridades mais dançadas, como em uma cena em que há uma grande ciranda, contribuíram no clima de cumplicidade. Por outro lado, composições com rupturas cadenciadas auxiliaram na atmosfera para a realização de movimentações lineares, como na cena do consumo desenfreado. No que concerne à sonoplastia, ela foi primeiramente idealizada na dramaturgia para, a seguir, ser desenvolvida nas oficinas de música, com base nas técnicas de percussão de Marcelo Rocha. Essas experiências de engajamento entre som e movimento estão vinculadas às bases do desenvolvimento infantil e oportunizam um regresso sensorial às origens do auto reconhecimento como um indivíduo que se diferencia do nicho ecológico, embora o integre.

A construção do esquema corporal permite a ritualização dos movimentos e a constituição do espaço operacional humano. Finalmente, a criação do espaço-tempo, por uma criança em cres- 
cimento é a conquista espiritual mais básica da infância e o fundamento efetivo do pensamento operacional e abstrato (VERDENZÖLLER, 2004, p. 189).

Essa vivência integradora, que reconhece a individualidade como parte do ambiente, resultou em uma potente comunhão energética, cujo valor simbólico e afetivo só pode ser vivenciado no ato da enunciação, mas cujos ecos devem permanecer em muitas outras experiências.

Por fim, a canção final da apresentação contém uma mensagem sobre a importância da natureza. É uma citação de parte de um rap de autoria de Malu Furno, no qual todo o grupo se coloca em comunhão com a plateia, convidando-a a ser cúmplice nessa ação ambiental, cantando e batendo palmas junto com o grupo em cena. Para esse momento, Marcelo Rocha criou um arranjo de percussão corporal, sem a utilização de nenhum outro instrumento, para que corpo e voz revelassem sua própria natureza, apoiada nos princípios ontogênicos mencionados.

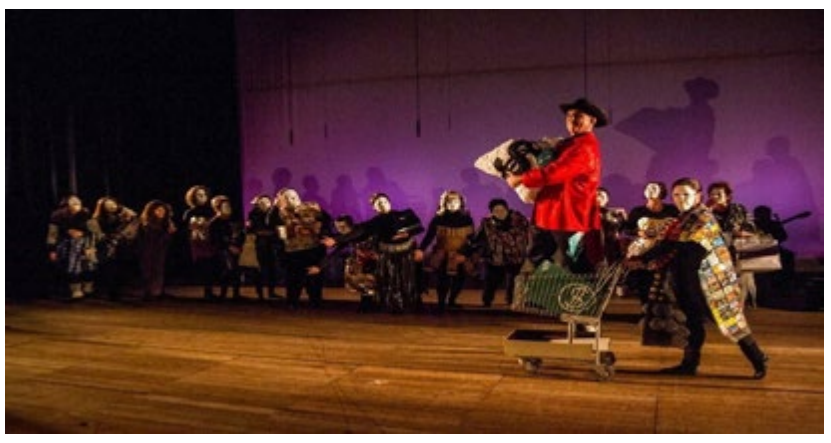

Figura 8.

Ecos de Cor e Cór - Salão de Atos da UFRGS, Porto Alegre, 2015. Fonte: Acervo do curso.

Máscaras sociais e ambientais

A oficina de máscaras foi realizada em distintas etapas ministradas por Jessé Oliveira. Os primeiros encontros foram dedicados às técnicas de construção das máscaras. Após a confecção de máscaras neutras, os alunos passaram por uma vivência de portagem de máscaras, na qual foram realizadas experiências práticas de interpretação teatral com a utilização dessas máscaras, evidenciando a importância do envolvimento corporal, em uma composição integrada que gera novas possibilidades de expressão. Além disso, durante os ensaios do espetáculo, Jessé Oliveira orientou, como assistente de direção, a construção das representações realizadas com a portagem de máscaras.

A proposta pedagógica da realização da oficina de máscaras estava embasada em diversos aspectos relacionados à Educação Ambiental, já que a confecção de máscaras exige um profundo contato da pessoa consigo mesma em uma relação de cumplicidade 
com quem confecciona. A moldagem da máscara é feita com uma pessoa imóvel, de olhos fechados e outra que aplica os materiais sobre o rosto da primeira para fazer o molde com cuidado e delicadeza, o que resulta em um momento de grande intimidade com o outro e consigo próprio.

Do ponto de vista biológico, o amor é a disposição corporal sob a qual uma pessoa realiza as ações que constituem o outro como um legítimo outro em coexistência. Quando não nos comportamos dessa maneira em nossas interações com o outro, não há fenômeno social. O amor é a emoção que fundamenta o social (MATURANA; VERDEN-ZOLLER, 2004, p. 235).

Ao criar um molde do seu próprio rosto, a pessoa estabelece uma nova percepção sobre si mesma, no toque que molda a máscara e nas sensações de proximidade com essa outra pessoa. Além disso, a construção da máscara exige confiança e cumplicidade, em um longo período de entrega. Nessa experiência, fica evidente o quanto nossa cultura ocidental contemporânea está carente de relações como esta, e o quanto nos privamos de compartilhar emoções de mútua aceitação, indispensáveis à construção de novas formas de vida que gerem efetivas melhorias ambientais.

Devido à limitação diante das emoções geradas em nós por nossa cultura, temos sido, no mundo ocidental, geralmente incapazes de perceber como nossas emoções, fisiologia e anatomia se entrelaçam necessariamente como um aspecto normal e espontâneo de nossa ontogenia (história de vida individual), desde a concepção até a morte (MATURANA; VERDEN-ZOLLER, 2004, p. 222).

Outro importante aspecto ecológico é que as máscaras aqui descritas foram confeccionadas com papel descartado e grude feito com substratos biodegradáveis, portanto, um material sustentável e acessível, fácil de conseguir, o que viabiliza a confecção das máscaras nas escolas, em atividades junto aos alunos.

No espetáculo Ecos de cor e cór, as máscaras foram utilizadas em dois momentos. Na primeira cena em que aparecem, foram usadas na interpretação dos animais. Essas máscaras foram confeccionadas pela aluna do curso Eloísa Danemberg, que associou seus conhecimentos como professora de Artes Plásticas às técnicas aprendidas na oficina, o que resultou num trabalho sensível e belo. A utilização das máscaras junto aos demais elementos dessa cena buscava propiciar imagens lúdicas e afetivas, em uma composição construída por meio de distintas técnicas de encenação, ampliando a percepção estética. A segunda cena em que aparecem as máscaras é a que representa o consumismo exacerbado. 
A utilização de máscaras neutras de rosto inteiro, completamente brancas e desprovidas de emoções, propunham a percepção da ausência de cumplicidade e de afeto entre os diversos personagens que circulam na cena. Essas máscaras foram confeccionadas pelos alunos durante as oficinas.

Em cena, as máscaras foram utilizadas para a criação de atmosferas teatrais completamente paradoxais, o que evidencia a multiplicidade de possibilidades expressivas desse adereço cênico. Essa percepção, para os alunos do curso, passou por uma vivência efetiva, pois eles perceberam o quanto a relação com a máscara resulta em distintas posturas corporais, ritmos de movimentos e maneiras de relação em cena. Por fim, a presença das máscaras em ambas as cenas contribuiu na constatação da possibilidade de distintas construções significativas, visto que podemos vestir ou tirar diversas máscaras cotidianamente. Vestir a máscara de um animal pode ser uma identificação do ser humano como parte da natureza. Ao mesmo tempo, retirar as máscaras de comportamentos padronizados pode ser uma forma de encontrar novos caminhos que levem à felicidade. A ambivalência das máscaras traz em si a contradição necessária ao pensamento dialético comprometido com a transformação:

Para os membros da comunidade que a vivem, uma cultura é um âmbito de verdades evidentes. Elas não requerem justificação e seu fundamento não se vê nem se investiga, a menos que no futuro dessa comunidade surja um conflito cultural que leve a tal reflexão (MATURANA, 2004, p. 112).

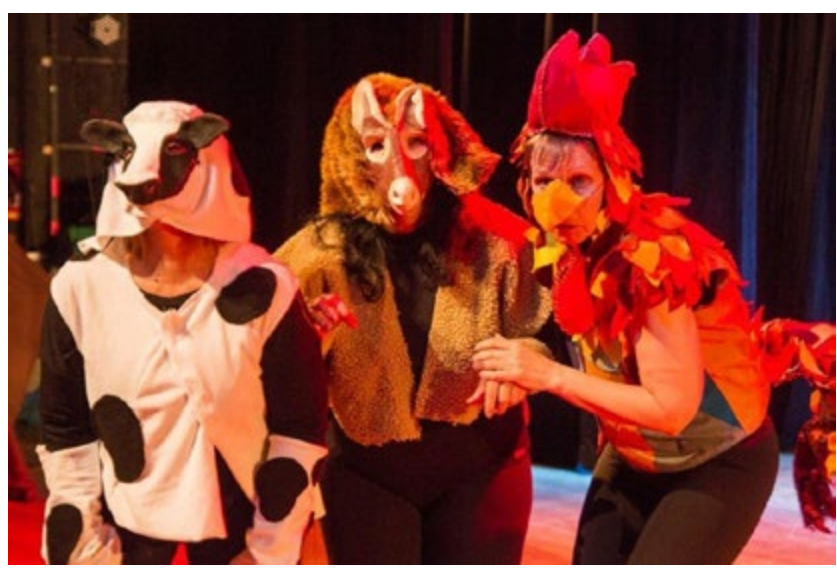

Figura 9. Ecos de Cor e Cór - Salão de Atos da UFRGS, Porto Alegre, 2015. Fonte: Acervo do curso.

\section{Ateliê Aberto}

Durante todo o período da disciplina, enquanto aconteciam oficinas e ensaios, foram realizados encontros de Ateliê Aberto, nos quais os brincantes atuadores Wagner Madeira, Éder Rosa e Carmen Lima confeccionavam materiais cenográficos e o brincante 
músico Marcelo Rocha confeccionava instrumentos de percussão, contando com a adesão de alunos que participaram do processo e contribuíram na construção dos materiais, além de aprender novas técnicas e compartilhar seus conhecimentos.

Amparados na concepção artístico-pedagógica da disciplina e da dramaturgia original, os brincantes desenvolveram as propostas de criação de materiais de forma que possibilitasse a participação ativa e criativa dos alunos do curso. Coerente com a proposta de Educação Ambiental, os adereços cênicos e instrumentos foram construídos, predominantemente, com materiais que foram reciclados em processos artesanais. A proposta pedagógica central dessa confecção era a percepção do valor simbólico dos materiais em si e a forma como sua reciclagem pode produzir significados que contribuam para uma consciência ecológica ou resultar, justamente, no inverso. Nesse sentido, propus que refletíssemos sobre a relação afetiva que se estabelece entre o brinquedo e quem o confeccionou, em especial no cotidiano escolar, quando, por exemplo, são criados brinquedos, flores e árvores de Natal construídos com garrafas pet, objetos plásticos e latas. O valor simbólico e afetivo desse tipo de construção acaba resultando em aceitação e estimulação da produção desses recipientes e dos conteúdos neles comercializados.

Estejamos ou não conscientes disso, o curso da história da humanidade segue o caminho do emocionar, e não o da razão ou o das possibilidades materiais ou dos recursos naturais. Isso se dá porque são nossas emoções que constituem os distintos domínios de ações que vivemos nas diferentes conversações em que aparecem os recursos, as necessidades ou as possibilidades (MATURANA, 2004, p. 110).

Dessa forma, quando o contato com uma flor real é substituído pelo contato com um objeto plástico criado artesanalmente, em cumplicidade com o professor, essa ação reforça o vínculo afetivo com o mesmo, justificando o sistema consumista que o gera. Esse tipo de ação, embora bem-intencionada, contribui na manutenção dos hábitos que são grandes responsáveis por danos ambientais da atualidade. Ou seja, ao invés de gerar novas condutas, o valor simbólico e afetivo desse tipo de reciclagem, apenas perpetua as práticas que precisariam ser transformadas.

No caso particular das culturas como linhagens humanas de modos de convivência, só se produz uma modificação numa dada comunidade humana quando uma nova forma de viver como rede de conversações começa a se manter geração após geração. Isso acontece cada vez que uma configuração no emocionar - e portanto uma nova configuração no agir - principia a fazer parte da forma corrente de incorporação cultural das crianças de tal comunidade e estas aprendem a vivê-la (MATURANA, 2004, p. 51). 
Por essa razão, em Ecos de cor e cór, os adereços vinculados às imagens da natureza são compostos majoritariamente por tecidos, papéis e similares. Já as cenas de consumo possuem adereços feitos com garrafas pet, lixo eletrônico e materiais análogos. Assim, os primeiros são associados ao afeto e à cooperação e os últimos, a comportamentos padronizados e ações individualistas. Por certo, a intenção não é criar um rótulo maniqueísta, mas sim, evidenciar o contraste emocional inerente aos processos artesanal e industrial, para que a percepção consciente dos objetos gere reflexões que influenciem escolhas e atitudes. A industrialização da produção cria um distanciamento do processo e enfoca o desejo de consumo, o qual é retroalimentado por si mesmo, transformando a si próprio no objetivo final. Por isso, adquirir não supre a necessidade e o momento presente é sempre uma expectativa de um porvir que não chegará nunca.

É nossa orientação cultural para a produção que nos insensibiliza, a cada momento, para o presente. É ela que dirige continuamente nossa atenção para um passado ou um futuro que só acontecem no espaço da descrição de nossas expectativas ou queixas, fora do domínio de nossas ações num dado momento. Para estar no presente devemos simplesmente estar no que estamos no momento (VERDEN-ZÖLLER, 2004, p. 140).

Para relativizar as possibilidades de reciclagem dos distintos materiais, os objetos de efeitos sonoros são utilizados em suas características reais, sem embelezamentos artificiais. Assim, bombonas plásticas para água ou placas metálicas denotam a possibilidade de múltiplas utilizações, sem, no entanto, serem maquiadas como artefatos naturais. Esses objetos fazem parte da realidade, e é preciso lidar com eles e com o que significam, sem ações paliativas e inócuas.

A única saída para essa situação é a recuperação de nossa consciência de responsabilidade individual por nossos atos, ao percebermos de novo que o mundo em que vivemos é configurado por nosso fazer (MATURANA, 2004, p. 114).

A intenção dessa abordagem foi a de aprofundar a reflexão sobre as ações pedagógicas (incluindo as artísticas) e a compreensão de que o caráter afetivo tem um valor simbólico muito mais amplo do que os frios discursos explicativos que jamais serão capazes de impor as profundas modificações necessárias às melhorias ambientais, já que "as culturas são sistemas essencialmente conservadores" (MATURANA, 2004, p. 86). A consciência ecológica precisa estar vinculada a reais modificações dos anseios diários em busca da felicidade. 
Só uma nova modificação na configuração de nossos desejos, em nossa coexistência, pode levar-nos a uma transformação que nos tire do patriarcado. E ela só nos poderá acontecer agora se assim o quisermos (MATURANA, 2004, p. 85).

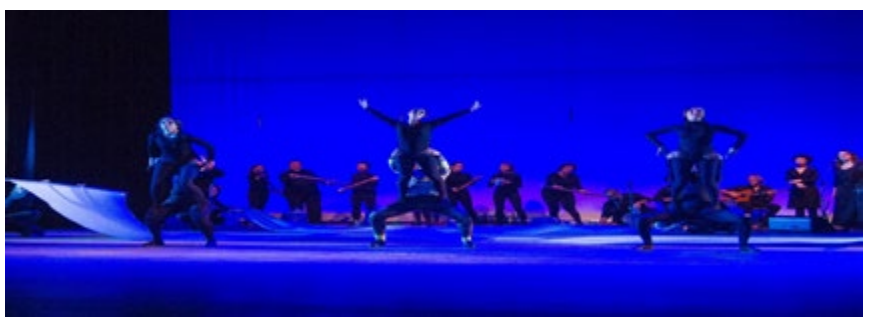

Figura 10.

Ecos de Cor e Cór

- Salão de Atos

da UFRGS, Porto

Alegre, 2015.

Fonte: Acervo

do curso.

\section{Ecos da Biologia do Amor na dramaturgia}

Ecos de cor e cór apresenta uma narrativa que perpassa distintos momentos da relação do ser humano com a natureza e ressalta que elas se alteram conforme as posturas assumidas nos diferentes contextos. A dramaturgia é inspirada na narrativa dos estudos de Humberto Maturana, apresentados no capítulo "Conversações matrísticas e patriarcais", presentes no livro Amar e Brincar (Palas Athena, 2011) e reconstrói um caminho apontado pelo autor, no qual a relação da humanidade com o meio ambiente se transforma no decorrer da História.

Pensamos que a história da humanidade seguiu a trajetória do emocionar. Em especial, ela seguiu o curso dos desejos, e não o da disponibilidade dos recursos e oportunidades naturais ou a trilha das ideias, valores e símbolos, como se estes existissem por si próprios (MATURANA; VERDEN-ZOLLER, 2004, p. 11).

Para Maturana, a sociedade, originariamente matriarcal, relacionava-se com a natureza harmoniosamente, e era parte integrante de um todo organicamente articulado. Posteriormente, com o surgimento da propriedade privada causado pela atividade pastoril, as relações se transformaram, passando da cooperação à competição, da cumplicidade à exploração, características da sociedade patriarcal.

O pensamento patriarcal é essencialmente linear, ocorre num contexto de apropriação e controle, e flui orientado primariamente para a obtenção de algum resultado particular porque não observa as interações básicas da existência. Por isso, o pensamento patriarcal é sistematicamente irresponsável. O pensamento matrístico, ao contrário, ocorre num contexto de consciência da interligação de toda a existência. Portanto, não pode senão viver continuamente no entendimento implícito de que todas as ações humanas têm sempre consequências na totalidade da existência (MATURANA, 2004, p. 47). 
Constata-se, assim, que Maturana considera os comportamentos matrísticos e patriarcais não vinculados a seres humanos masculinos e femininos, visto que ambos fazem parte das configurações culturais que geram os dois sistemas. $O$ autor defende que o ser cultural, ao perceber os fundamentos emocionais das suas ações, pode se deixar influenciar pelo entendimento e pela percepção, com vistas a modificar o emocionar e, portanto, a cultura gerada por ele.

\begin{abstract}
A história da humanidade seguiu e segue um curso determinado pelas emoções e, em particular, pelos desejos e preferências. São estes que, em qualquer momento, determinam o que fazemos ou deixamos de fazer, e não a disponibilidade do que hoje conotamos ao falar de recursos naturais ou oportunidades econômicas, os quais tratamos como condições do mundo cuja existência seria independente do nosso fazer. Nossos desejos e preferências surgem em nós a cada instante, no entrelaçamento de nossa biologia com nossa cultura e determinam, a cada momento, nossas ações. São eles, portanto, que definem, nesses instantes, o que constitui um recurso, o que é uma possibilidade ou aquilo que vemos como uma oportunidade (MATURANA, 2004, p. 36).
\end{abstract}

Com base nessas assertivas, construí a dramaturgia de Ecos de cor e cór, sobre a qual pretendo refletir mais profundamente em outro estudo, e posteriormente, apresentar minhas considerações detalhadamente. A interpretação realizada pelo grupo em Ecos de cor e cór foi uma ação da mais profunda VERDADE, da qual derivou uma poderosa experiência estética, sensorial e social, tanto para quem participou do processo quanto para os que puderam assistir ao trabalho.

Como refere Maturana, "na origem de uma nova cultura o novo emocionar surge como uma variação ocasional e trivial do emocionar cotidiano próprio da cultura antiga" (2004, p.50). Foi no que todos acreditamos ao realizar esse trabalho, investindo nele, sensibilidade, afeto, cumplicidade, conhecimento e dedicação. A transformação é possível. Ecos de cor e cór ecoa em todos nós.

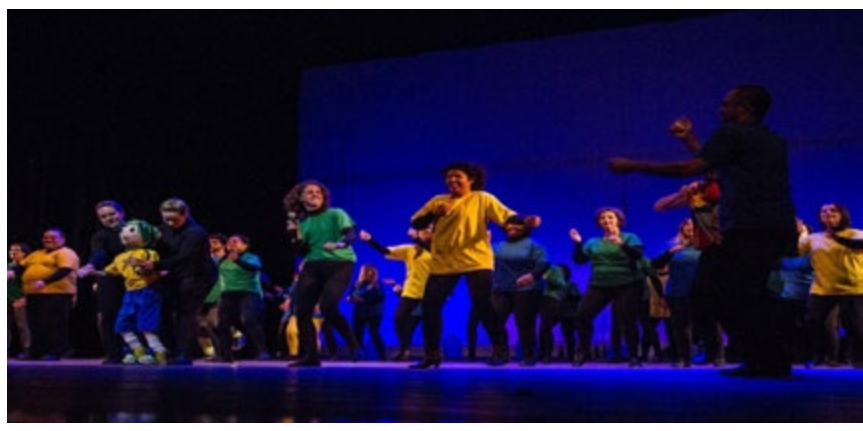

Figura 11. Ecos de Cor e Cór Salão de Atos da UFRGS, Porto Alegre, 2015. Fonte: Acervo do curso. 


\section{REFERENNCIAS}

BARBA, Eugenio; SAVARESE, Nicola. A arte secreta do ator: Dicionário de antropologia teatral. São Paulo: Hucitec Ed. da Unicamp, 1995.

BOAL, Augusto. Teatro do Oprimido e outras poéticas políticas $8^{\mathrm{a}}$ ed. - Rio de Janeiro: Civilização Brasileira, 2008.

BRECHT. Bertold. Teatro dialético: Ensaios. Rio de Janeiro: Civilização Brasileira, 1967.

BRECHT. Bertold. La política en el teatro. Editorial Alfa Argentina: Buenos Aires, 1972.

CAMAROTTI, Marco. A linguagem no teatro infantil. Recife: UFPE, 2005.

DE MARINIS, Marco. En busca del actor y del espectador. Comprender el teatro II. Buenos Aires: Galerna, 2005.

FREIRE, Paulo. Pedagogia do Oprimido. $60^{\mathrm{a}}$ edição. Rio de Janeiro/ São Paulo: Paz \& Terra, 2016.

FURNO, Malu. Brasileco: o início da aventura. Porto Alegre: Eco Brasil Produções, 2010.

GIL, João Pedro Alcantara. Para além do jogo. Tese (Doutorado). Universidade Federal de Santa Maria. Programa de Pós-Graduação em Educação, Santa Maria, 1999.

JUGUERO, Viviane. Bando de Brincantes: um caminho dialético no teatro para crianças. Dissertação (mestrado). Universidade Federal do Rio Grande do Sul. Programa de Pós-Graduação em Artes Cênicas, Porto Alegre, 2014.

MATURANA, Humberto; VERDE-ZOLLER, Gerda. Amar e Brincar. São Paulo: Palas Athena, 2004.

PAVIS, Patrice. A análise dos espetáculos. São Paulo: Perspectiva, 2010. PUPO, Maria Lúcia de Souza Barros. No reino da desigualdade: Teatro infantil em São Paulo nos anos setenta. São Paulo: Pespectiva, 1991.

VERSIANI, Daniela Beccaccia. Autoetnografia: uma alternativa conceitual. Letras de Hoje, v. 37, n. 4, 2013.

UBERSFELD, Anne. Para ler o teatro. São Paulo: Perspectiva, 2010. 